\title{
Rancang Bangun Sistem Pakar Diagnosa Penyakit Tuberkulosis (TBC) dengan Metode Forward Chaining
}

\author{
Alif Diah Lestyaningrum ${ }^{1}$; Sri Anardani ${ }^{2}$ \\ Program Studi S1 Teknik Informatika Sekolah Tinggi Teknik Dharma Iswara Madiun \\ Jl.Aurino.14-16 Madiun Telp. 0351-469128 \\ ${ }^{1}$ stt.2012b.alif.122112040@gmail.com; ªnardani26@hotmail.com
}

\begin{abstract}
ABSTRAK
Tuberkulosis atau TBC adalah penyakit infeksi yang disebabkan oleh bakteri Mycobacterium tuberculosis. Penyakit ini paling sering menyerang paru-paru walaupun pada sepertiga kasus menyerang organ tubuh lain dan ditularkan orang ke orang. Ini juga salah satu penyakit tertua yang diketahui menyerang manusia.. Oleh karena itu diperlukan sebuah sistem pakar yang mampu memberikan informasi diagnosa penyakit tuberkulosis. Sistem pakar adalah suatu program komputer cerdas yang menggunakan knowledge (pengetahuan) dan prosedur inferensi untuk menyelesaikan masalah yang cukup sulit sehingga membutuhkan seorang yang ahli untuk menyelesaikannya. Pengetahuan adalah sebuah kekuatan yang dapat memecahkan suatu masalah yang kita temui sehari-hari. Penelitian ini bertujuan untuk agar mempermudah dalam menentukan gejala tuberkulosis. Metode yang dipergunakan dalam sistem ini adalah Forward Chaining. Forward Chaining adalah strategi penarikan kesimpulan yang dimulai dari sejumlah fakta-fakta yang telah diketahui, untuk mendapatkan suatu fakta baru dengan memakai rule-rule yang memiliki premis yang cocok dengan fakta dan terus dilanjutkan sampai mendapatkan tujuan atau sampai tidak ada rules yang punya premis yang cocok atau sampai mendapatkan fakta. Pada sistem pakar ini memberikan hasil berupa hasil diagnosa dan solusi penyakit.
\end{abstract}

\section{Kata kunci : Pakar Diagnosa, Tuberkulosis (TBC), Forward Chaining}

\section{PENDAHULUAN}

Tuberkulosis atau TBC adalah penyakit infeksi yang disebabkan oleh bakteri Mycobacterium tuberculosis. Penyakit ini paling sering menyerang paru-paru walaupun pada sepertiga kasus menyerang organ tubuh lain dan ditularkan orang ke orang. Ini juga salah satu penyakit tertua yang diketahui menyerang manusia.Penyakit tuberkulosis selama ini hanya dianggap penyakit yang ringan oleh masyarakat tanpa diketahui bahwa penyakit tuberkulosis ini adalah salah satu penyakit yang mematikan apabila tidak ditangani dengn cepat dan tepat.

Dalam artikel Depkes RI mengatakan bahwa India, Cina dan Indonesia berkontribusi $>50 \%$ dari seluruh kasus TB yang terjadi di 22 negara.Indonesia menempati peringkat ke3 setelah India dan Cina.Beban TB di Indonesia masih sangat tinggi, khususnya mengenai kesembuhan yang ada.Setiap hari sekitar 300 orang meninggal karena TB di Indonesia.Lebih dari setengah juta pasien TB baru di Indonesia setiap tahun.
TB adalah pembunuh nomor satu penyakit menular dan merupakan peringkat 3 dalam daftar 10 penyakit pembunuh tertinggi di Indonesia, yang menyebabkan sekitar 88.000 kematian setiap tahunnya. Sebagian besar penderita TB adalah usia produktif yaitu berkisar 15-55 tahun. Faktor yang memengaruhi kemungkinan seseorang menjadi pasien TB adalah daya tahan tubuh yang rendah, di antaranya infeksi HIV/AIDS dan malnutrisi (gizi buruk), faktor lingkungan yaitu ventilasi, kepadatan hunian, faktor perilaku, kesehatan perumahan, lama kontak dan kosentrasi kuman.

Berdasarkan permasalahan yang ada tersebut maka penulis mengambil judul "Rancang Bangun Sistem Pakar Diagnosa Penyakit Tuberkulosis (Tbc) Dengan Metode Forward Chaining". Diharapkan sistem pakar ini dapat membantu mendiagnosa gejala awal tuberkulosis secara efektif dan efisien. 


\section{KAJIAN PUSTAKA}

\section{Konsep Dasar Sistem Pakar}

\begin{tabular}{ccc}
\multicolumn{2}{c}{ Sistem pakar adalah suatu } \\
program komputer cerdas yang
\end{tabular} menggunakan knowledge (pengetahuan) dan prosedur inferensi untuk menyelesaikan masalah yang cukup sulit sehingga membutuhkan seorang yang ahli untuk menyelesaikannya. Pengetahuan adalah sebuah kekuatan yang dapat memecahkan suatu masalah yang kita temui sehari-hari. Sistem pakar adalahprogram Artificial Intellenge yang menggabungkan pangkalan pengetahuan (knowledge base) dengan sistem inferensi. Kecerdasan buatan atau Artificial Intellenge (AI) dapat didefinisikan sebagai sub bidang pengetahuan komputer yang khusus ditujukan untuk membuat software dan hardware yang sepenuhnya biasa menirukan beberapa fungsi otak manusia. Karena itu diharapkan komputer bisa membantu manusia didalam berbagai masalah yang sangat rumit (Wisnu dalam Wiwi, 2015).

Sistem pakar (expert system) adalah sistem yang berusaha mengadopsi pengetahuan manusia ke komputer, agar komputer dapat menyelesaikan masalah seperti yang biasa dilakukan oleh para ahli. Sistem pakar yang baik dirancang agar dapat menyelesaikan suatu permasalahan tertentu dengan meniru kerja dari para ahli. Dengan sistem pakar ini, orang awampun dapat menyelesaikan masalah yang cukup rumit yang sebenarnya hanya dapat diselesaikan dengan bantuan para ahli. Bagi para ahli, sistem pakar ini juga akan membantu aktivitasnya sebagai asisten yang sangat berpengalaman.Tiga komponen utama yang tampak secara virtual pada setiap sistem pakar adalah basis pengetahuan, mesin inferensi dan antarmuka pengguna. Sistem pakar dapat pula berisi komponen tambahan sebagai berikut: subsistem akuisisi pengetahuan, blackboard, subsistem penjelasan dan sistem perbaikan pengetahuan. Kebanyakan sistem pakar saat ini tidak berisi komponen perbaikan pengetahuan (Kusumadewi dalam Dwi, dkk, 2014).
Menurut Rika (2012) Komponen yang terdapat dalam struktur sistem pakar ini adalah knowledge base (rules),inference engine, working memory, explanation facility, knowledge acquisition facility, user interface.

\section{Pengertian Tuberkulosis (TBC)}

Menurut Adhi (2013) dalam jurnalnya yang berjudul Perancangan Aplikasi Sistem Pakar untuk Mendiagnosa penyakit pada Manusia.Tuberkulosis atau TBC adalah penyakit infeksi yang disebabkan oleh bakteri Mycobacterium tuberculosis. Penyakit ini paling sering menyerang paru-paru walaupun pada sepertiga kasus menyerang organ tubuh lain dan ditularkan orang ke orang. Ini juga salah satu penyakit tertua yang diketahui menyerang manusia. Jika diterapi dengan benar tuberkulosis yang disebabkan oleh kompleks Mycobacterium tuberculosis, yang peka terhadap obat, praktis dapat disembuhkan. Tanpa terapi tuberkulosa akan mengakibatkan kematian dalam lima tahun pertama pada lebih dari setengah kasus. Tuberkulosis masih merupakan penyakit infeksi saluran napas yang tersering di Indonesia. Keterlambatan dalam menegakkan diagnosa dan ketidakpatuhan dalam menjalani pengobatan mempunyai dampak yang besar karena pasien Tuberkulosis akan menularkan penyakitnya pada lingkungan,sehingga jumlah penderita semakin bertambah.

Menurut Hasan (dalam Tika dkk, 2014), "Tuberkulosis merupakan infeksi yang disebabkan oleh bakteri Mikrobakterium tuberculosis (dan kadangkadang oleh M.Bovis dan africanum). Organisme ini disebut pula sebagai basil tahan asam".

\section{Forward Chaining}

Forward Chaining adalah strategi penarikan kesimpulan yang dimulai dari sejumlah fakta-fakta yang telah diketahui, untuk mendapatkansuatu fakta baru dengan memakai rule-rule yang memiliki premis yang cocok dengan fakta dan terus dilanjutkan sampai mendapatkan tujuan atau sampai tidak ada rules yang punya premis yang cocok atau sampai mendapatkan fakta (Puput, dkk 2015:26). 
Menurut Deefa (dalam Wiwi, 2015) menyatakan bahwa Forward Chaining adalah teknik pencarian yang dimulai dengan fakta yang diketahui, kemudian mencocokkan fakta-fakta tersebut dengan bagian IF dari rules IF-THEN. Bila ada fakta yang cocok dengan bagian IF, maka rule tersebut dieksekusi. Bila sebuah rule dieksekusi, maka sebuah fakta baru (bagian THEN) ditambahkan ke dalam database. Setiap kali pencocokan, dimulai dari rule teratas. Setiap rule hanya boleh dieksekusi sekali saja. Proses pencocokan berhenti bila tidak ada lagi rule yang bisa dieksekusi. Metode pencarian yang digunakan adalah Deptth-Firstf Search(DFS), Breadth-First Search (BFS) atau Best First Search.

\section{Konsep Dasar WEB}

Menurut Octavia (2013), "Website atau situs web juga dapat diartikan sebagai kumpulan halaman yang menampilkan informasi data, teks data gambar diam atau gerak, data animasi, suara, video dan atau gabungan dari semuanya, baik yang bersifat statis maupun dinamis yang membentuk suatu rangkaian bangunan yang saling terkait dimana masingmasing dihubungkan dengan jaringan-jaringan halaman (hyperlink). Bersifat statis apabila isi informasi website tetap, jarang berubah, dan isi informasinya searah hanya dari pemilik website. Bersifat dinamis apabila isi informasi website selalu berubah ubah, dan isi informasinya interaktif dua arah berasal dari pemilik serta pengguna website".

Menurut Andrea(2014:11), Website adalah halaman informasi yang disediakan melalui jalur internet sehingga bias diakses di mana pun selama anda terkoneksi dengan jaringan internet. Website merupakan komponen atau kumpulan komponen yang terdiri dari teks, gabar, suara, sehingga lebih merupakan media informasi yang menarik untuk dikunjungi.

\section{Metode Waterfall}

Menurut Rosidi dkk, (2013) menyatakan bahwa Metode waterfall adalah metode yang sifatnya sistematik dan sekuensial, dimana tiap tahap yang dilalui harus menanti tahap yang sebelumnya selesai dikerjakan.

\section{METODOLOGI PENELITIAN}

Dilaksanakan selama 3 bulan, yaitu dimulai pada tanggal April 2016 sampai dengan Juni 2016, dan penelitian dilakukan pada saat jam buka praktek setiap dokter. Penelitian dilaksanakan menggunakan pemodelan pengembangan model waterfall. Metode waterfall adalah metode yang sifatnya sistematik dan sekuensial, dimana tiap tahap yang dilalui harus menanti tahap yang sebelumnya selesai dikerjakan (Rosidi dkk, 2013).

Adapun proses atau tahapan dari penelitian pada Laporan Tugas Akhir digambarkan dalam sebuah flowchart.

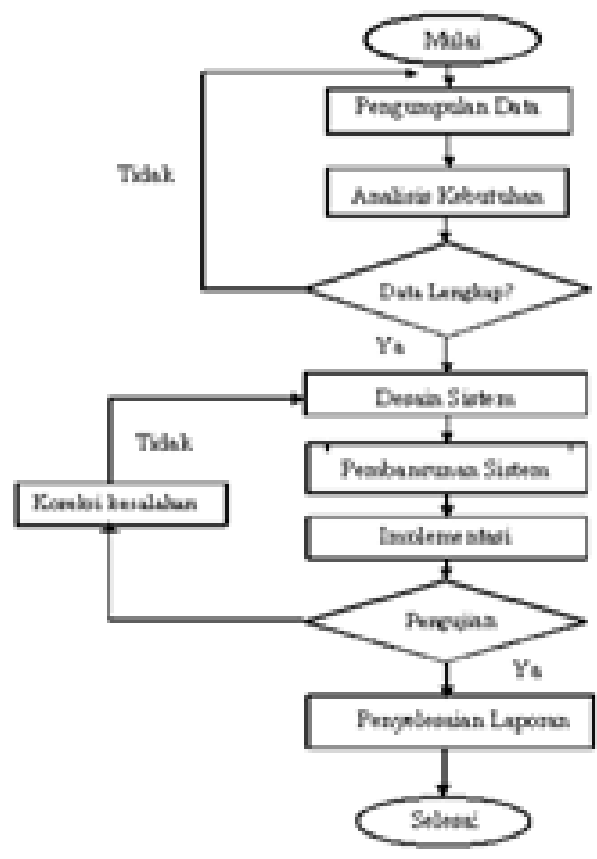

Gambar 1 Rancangan Penelitian

\section{ANALISIS DAN PERANCANGAN SISTEM Analisa Kegunaan Sistem}

Sistem pakar diagnosa penyakit Tuberkulosis (TBC) dapat didefinisikan sebagai sistem yang mampu dan berguna untuk masyarakat salah satunya adlah sebagai berikut ini:

1. Membantu masyarakat umum untuk mendiagnosa penyakit yang sedang diderita seorang pasien.

2. Memberikan informasi dan pengetahuan kepada masyarakat tentang pengertian 
Tuberkulosis (TBC) secara umum, mulai dari jenisnya, gejala - gejala awal dan solusi pengobatan sementara pada penderita, dan pencegahannya.

Sistem pakar yang dirancang dan dibangun ini memiliki kemampuan untuk mendiagnosa jenis penyakit Tuberkulosis (TBC) yang diharapkan dapat membantu masyarakat umum khususnya untuk mendeteksi gejala- gejala awal nya.Yang tidak terlepas dari peran dokter atau rumah sakit sebagai pihak kesehatan untuk menindak lanjuti pengobatan pasien Tuberkulosis (TBC) secara tepat dan spesifik.

\section{Analisa Kebutuhan Sistem}

1. Kebutuhan Fungsional

a. Sistem dapat membantu mendiagnosa penyakit Tuberkulosis (TBC) dengan jenis $\mathrm{TB}$ paru dan TB kelenjar.

b. Sistem dapat membantu memberikan solusi pada penderita.

c. Sistem dapat memberikan informasi kepada user mengenai penyebab, gejala penyakit Tuberkulosis (TBC).

2. Kebutuhan nonfungsional

a. Perangkat Keras (Hardware)

Perangkat keras yang dibutuhkan sebagai pendukung berjalannya sistem tersebut adalah komputer atau laptop dengan spesifikasi sebagai berikut:

1) Minimum processor intel core to duo keatas.

2) Minimal RAM $1 \mathrm{~Gb}$.

3) HDD 160Gb.

4) Keyboard

5) Mouse

6) LCD monitor

b. Perangkat Lunak (Software)

Perangkat lunak yang di butuhkan sebagai pendukung sistem adalah :

1) Minimum sistem operasi yang di gunakan Windows 7 keatas.

2) Web browser Mozilla Firefox atau Google Chrome.

3) Xampp sebagai SQL server untuk membuat database di phpMyAdmin.

4) Aplikasi Dreamweawer

c. Pengguna (Brainware)

Pengguna dari sistem ini adalah admin dan user.

\section{Mekanisme Inferensi}

1. Metode Forward Chaining

Mekanisme infefrensi dengan metode chaining untuk penyelesaian sistem pakar tuberculosis yang melalui beberapatahapan sederhana karena menggunakan enkripsi logikadalam kaidah produksi dengan menggunakan langkah-langkah sebagai berikut ini :

a. Langkah 1, mengajukan beberapa pertanyaan pada pengguna.

b. Langkah 2, simpanan inputan dari pengguna sebagai premis rule.

c. Langkah 3, cek rule berdasarkan inputan, jika langkah 1 sampai langkah 3. Jika tidak ditemukan maka berikan default output.

d. Langkah 4, berikan pengendalian.

\section{Basis Pengetahuan}

1. Data Tuberkulosis Paru dan Tuberkulosis Kelenjar

Merupakan data mengenai gejala -gejala dari penyakit tuberkulosis paru dan kelenjar yang menggunakan kode-kode untuk mempermudah dalam perhitungan dengan forward chaining.

2. Basis Pengetahuan

a. Tabel Penyakit

Merupakan data dari penyakit yang sedang dibahas dengan pengkodean sebagai berikut ini:

Tabel 1 Tabel Penyakit

\begin{tabular}{|l|l|l|l|}
\hline NO & NAMA PENYAKIT & KODE & \multicolumn{1}{|c|}{ GE JALA -GEJALA } \\
\hline 1 & Tuberkulosis Paru - & P0001 & a) Batuk berdahak lebih dari 3 \\
& Paru & & Mnggu \\
b) Demam \\
c) Sesaknapas \\
\end{tabular}

b. Tabel Gejala

Merupakan tabel dimana gejalagejaladari tuberculosis disebutkan dengan kode sebagai berikut: 
Tabel 2 Tabel Gejala

\begin{tabular}{|c|c|c|}
\hline No & GEJALA - GEJALA & KODE \\
\hline 1 & Berat badan menurun & D0001 \\
\hline 2 & Napsu makan berkurang & D0002 \\
\hline 3 & Batuk//atuk kronis/ / berdahak / / lebih dari 3 mingsur & D0003 \\
\hline 4 & Demam & D0004 \\
\hline 5 & Sesal napas. & D0005 \\
\hline 6 & Nyeri dada & D0006 \\
\hline 7 & Malaise (sakit kepala / nyeri stot) & D0007 \\
\hline 8 & Batul- berdarah. & D0008 \\
\hline 9 & Muncul beniglan pada leher / ketials/ paha / pungsung & D0009 \\
\hline 10 & Demam berkepanjangan $38^{\circ}$ & D0010 \\
\hline 11 & \begin{tabular}{|l|l} 
Batuk kronis. \\
\end{tabular} & D0011 \\
\hline 12 & Keringat pada malam hari & D0012 \\
\hline 13 & Tidak enak badan & D0013 \\
\hline
\end{tabular}

c. Tabel Rule

Merupakan tabel aturan ada forward chaining yaitu IF...THEN

Tabel 3 Tabel Rule

\begin{tabular}{cll}
\hline RULE & \multicolumn{1}{c}{ IF } & THEN \\
\hline 1 & D0001, D0002, & P0001 \\
& D0003, D0004, & \\
& D0005, & \\
& D0006, D0007, & \\
& D0008 & \\
2 & D0001, D0002, & P0002 \\
& D0009, D0010, & \\
& D0011, D0012, & \\
& D0013 & \\
\hline
\end{tabular}

d.Tabel Keputusan

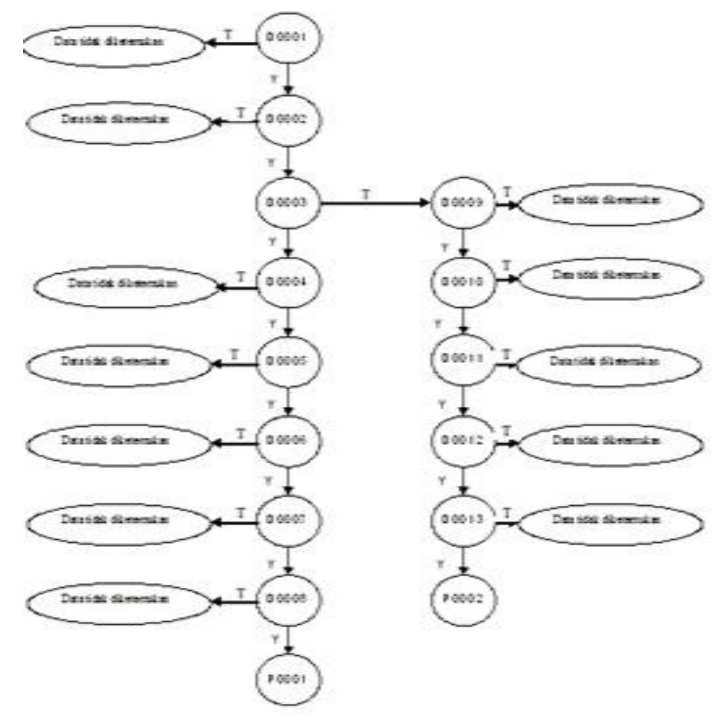

Gambar 2 Tabel Keputusan

\section{Perancangan Sistem}

1. Flowcart Login

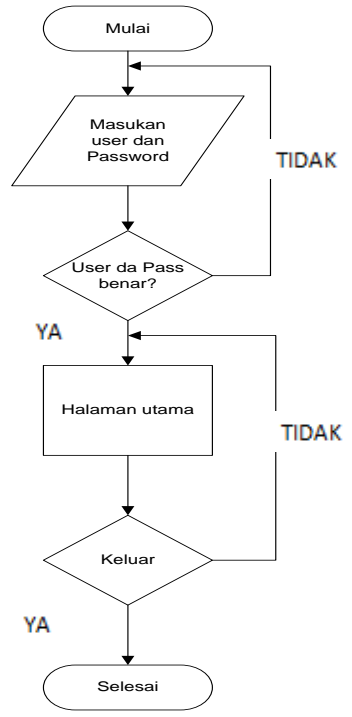

Gambar 3 Flowchart Login

2. Flowcart Menu Sistem Pakar

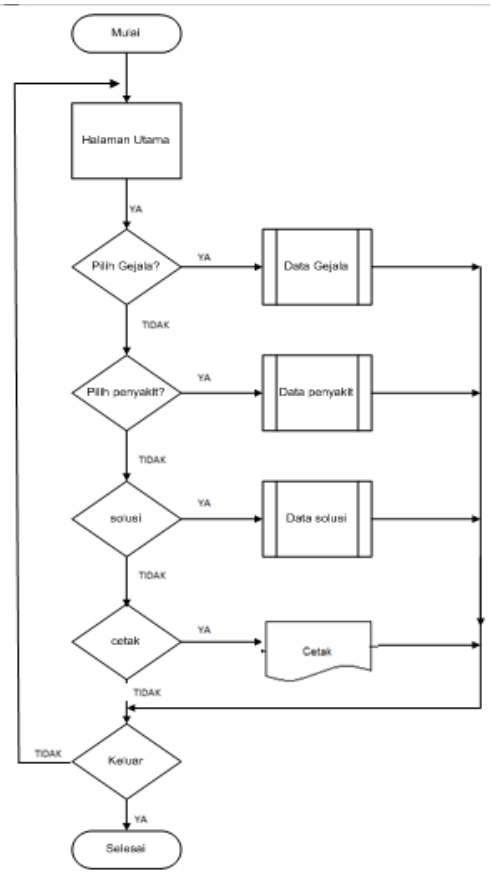

Gambar 4 Flowchart Menu Sistem Pakar

\section{Data Flow Diagram}

1. Diagram Konteks

Gambar di bawah ini merupakan Diagram Konteks atau sering disebut juga dengan Data Flow Diagram (DFD) level 0 dari Rancang bangun sistem pakar diagnosa penyakit tuberculosis (TBC) dengan metode Forward Chaining yang akan dibangun. Diagram Konteks 
menjelaskan hubungan antara sistem pakar dengan entity-entity lain yang berada diluar sistem. Diagram Konteks (DFD Level 0)dari Rancang bangun sistem pakar diagnosa penyakit tuberculosis (TBC) dengan metode Forward Chaining adalah sebagai berikut:

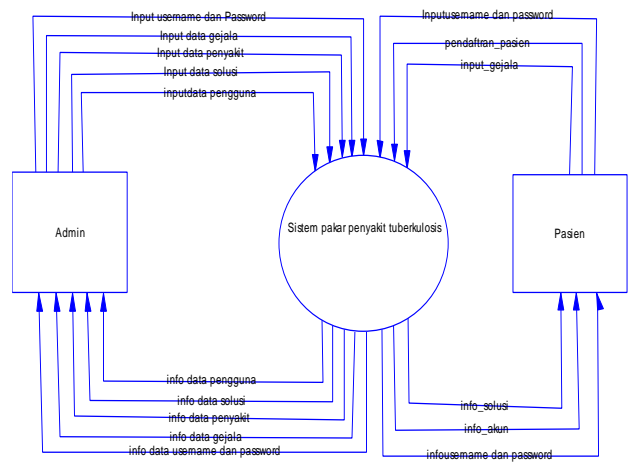

Gambar 5 Diagram Konteks (DFD Level 0)

2. DFD Level 1 (DFD Level 1)

Gambar di bawah ini merupakan Data Flow Diagram (DFD)/Diagram Alir Data level 1 dari dari Rancang bangun sistem pakar diagnosa penyakit tuberculosis (TBC) dengan metode Forward Chaining yang yang akan dibangun. Diagram Alir Data level 1 menjelaskan proses-proses utama yang terjadi di dalam sistem yang dipengaruhi oleh entity-entity diluar sistem. DFD Level 1.

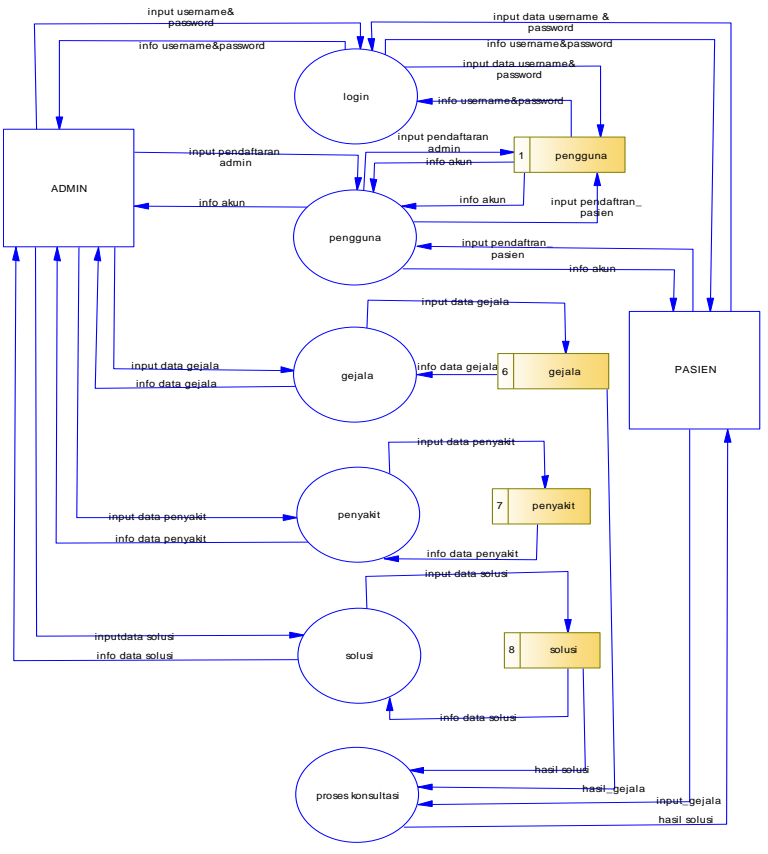

Gambar 6 Data Flow Diagram Level 1 (DFD Level 1)

\subsection{ERD ( Entity Relation Diagram)}

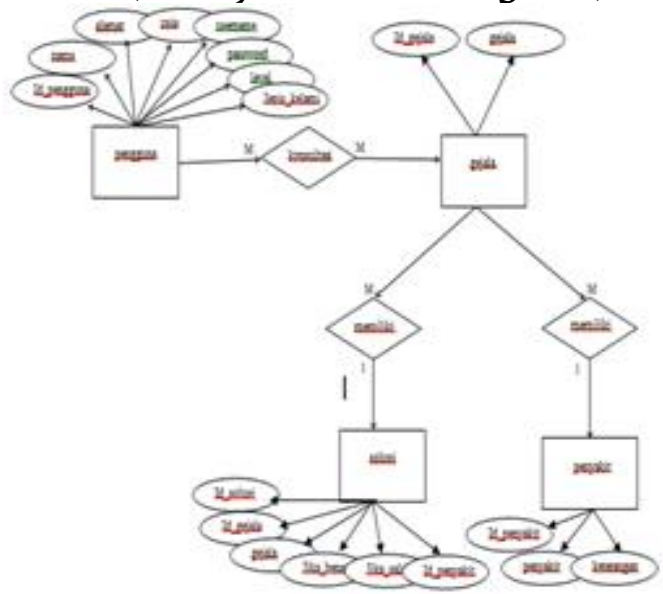

Gambar 7 ERD

\section{IMPLEMENTASI SISTEM}

\section{Form Beranda}

Form ini tampil saat pertama kali program di jalankan.FormBeranda berfungsi untuk masuk ke form menu utama dan mengaktifkan menu-menu yang terdapat pada formmenu utama. Ada beberapa pilihan untuk membuka form selanjutnya.

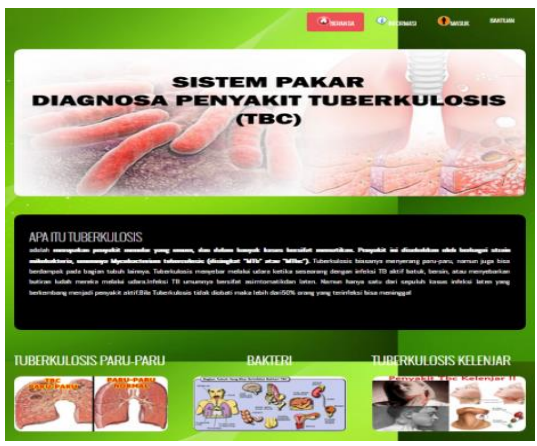

Gambar 8. Form Beranda

\section{Form Informasi}

Form informasi merupakan Form yang berisi tentang informasi bagaimana pencegahan terhadap tuberculosis pada penderita sehingga dapat menjadi ilmu pengetahuan bagi pengguna. Form ini berada pada form utama.

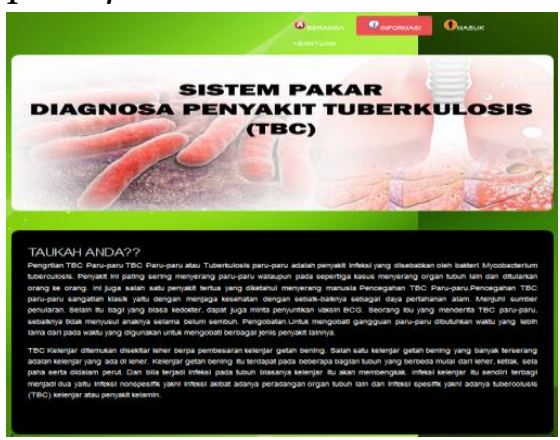

Gambar 9 Form Informasi 


\section{Form Masuk Admin dan User}

Form ini tampil saat setelah kita memilih menu Masuk.Form Masuk berfungsi untuk masuk ke formdiagnosa untuk melakukan pemilihan gejala yang sedang dialami. Jika admin maupun pengguna salah memasukkan username atau password maka aplikasi tidak bisa berjalan atau tidak bisa akan masuk ke menu diagnosa.

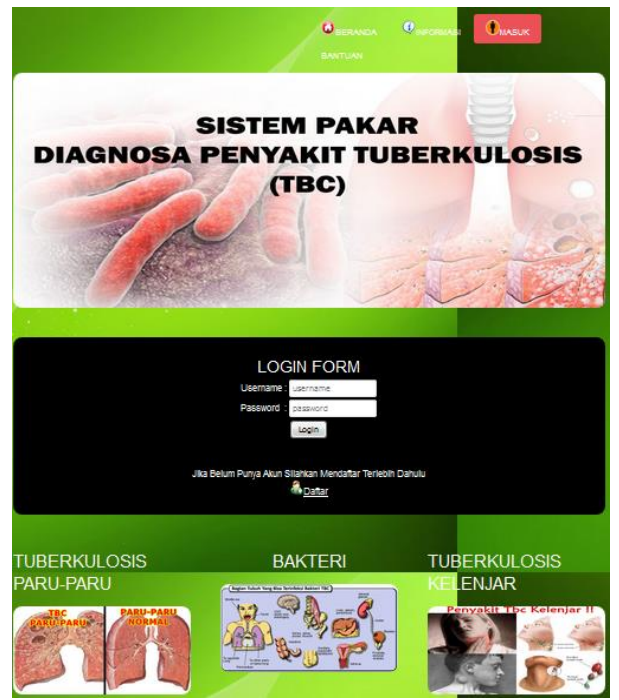

Gambar 10 Form Daftar

\section{Form Pendaftaran}

Form ini tampil saat user belum mempunyai username dan password sehingga dapat daftar terlebih dahulu untuk dapat masuk ke sistem pakar. Berikut ini adalah form penadaftarannya :

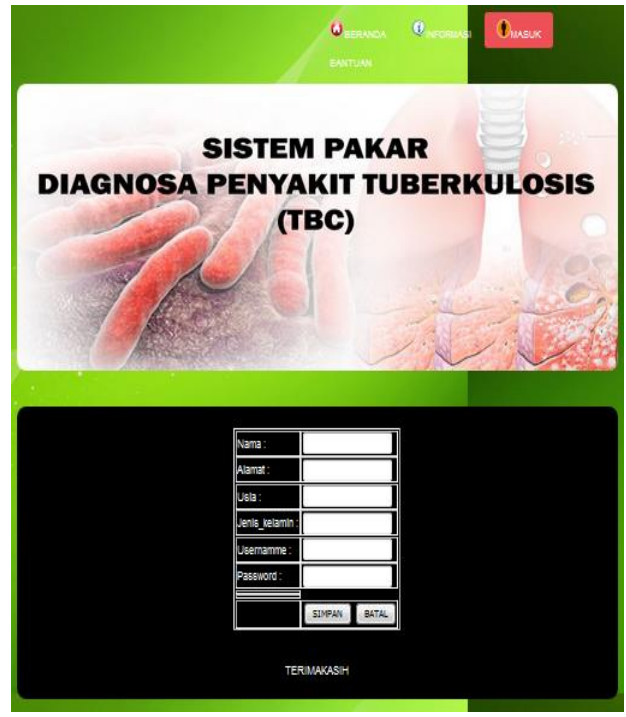

Gambar 11 Form Pendaftaran

\section{Form Bantuan}

Form ini berisi tentang Bagaiman pengguna dapat mempergunakan web atau menjalankan web untuk diagnosa dan mendapatkan hasil diagnosa:

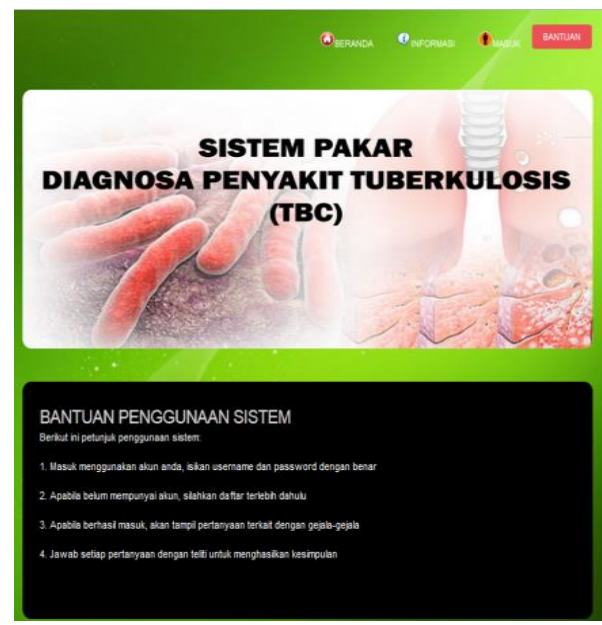

Gambar 12 Form Bantuan

\section{Form Admin}

Form ini berisi pengolahan yang dilakuakan oleh admin untuk

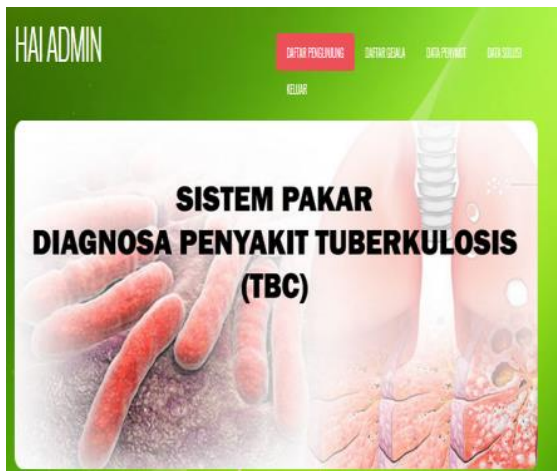

Gambar 13 Form Admin

\section{Form Daftar Pengunjung}

Form ini berisi admin mengolah atau melihat data dari pengunjung yang datang dalam website :

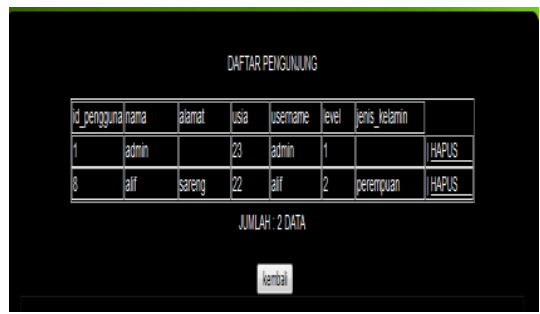

Gambar 14 Daftar Pengunjung

\section{Form Daftar Gejala}

Form ini berisi admin mengolah atau menambah data-data gejala mengenai data gejala tuberkulosis : 


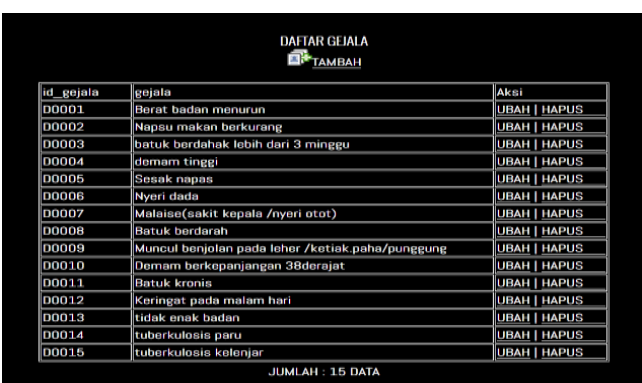

Gambar 15 Daftar Gejala

\section{Form Daftar Penyakit}

Form ini berisi admin mengolah atau melihat data dari daftar penyakit dari penyakit Tuberkulosis :

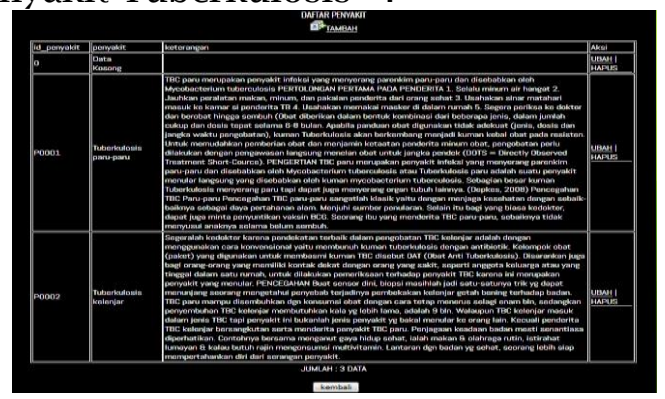

Gambar 16 Daftar Penyakit

\section{Form Solusi}

Form ini berisi tentang beberapa solusi tentang penyakit tuberkulosis yang dapat diedit oleh admin saja :

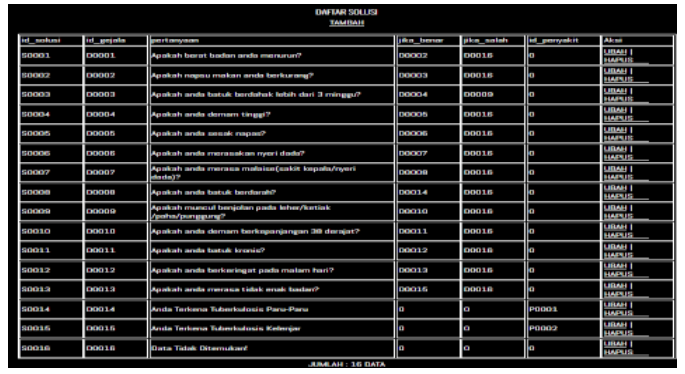

Gambar 17 Daftar Penyakit

\section{Form Diagnosa}

Form ini berisi penyakit yang mana didalam form tersebut pengunjung harus memilih salah satu dari jawaban untuk menentukan penyakityang diderita :

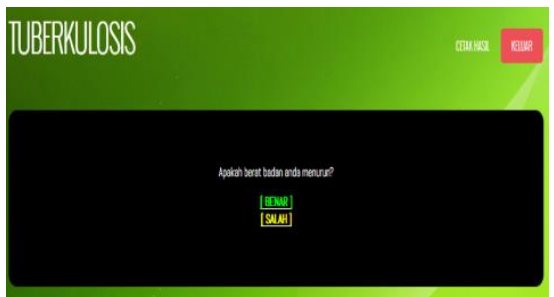

Gambar 18 Form Diagnosa

\section{Hasil}

Form ini berisi tentang hasil dari diagnosa yang telah dilakukan oleh pengguna :

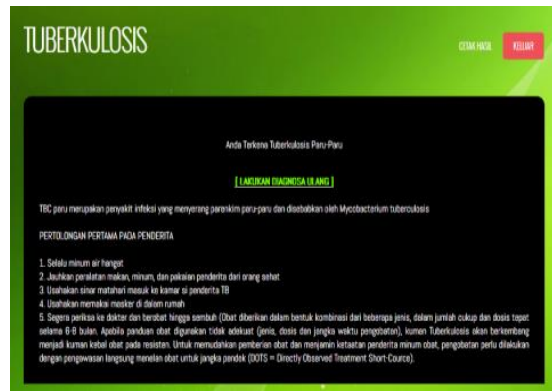

\section{Form Cetak}

Gambar 19 Form Hasil

Form ini berisi hasil diagnosa yang siap dicetak untuk para pengunjung:

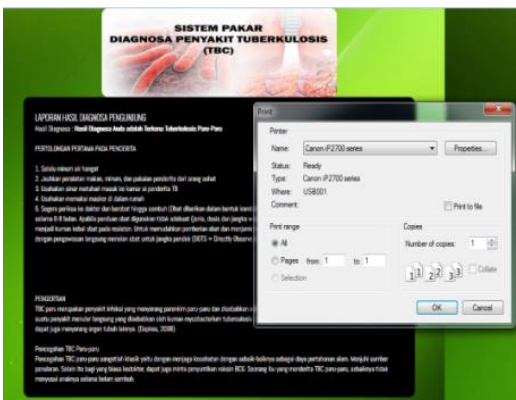

Gambar 20 Form Hasil

\section{PENUTUP}

Kesimpulan

1. Sistem pakar diagnosa penyakit yang telah dibuat oleh penulis diharapkan dapat dan bermanfaat bagi para pengguna umum untuk mendeteksi gejala penyakit tuberkulosis.

2. Sistem pakar diagnosa penyakit tuberkulosis ini diharapkan membantu pengguna mencari gejala yang perlukan dengan lebih cepat, mudah dan kapan saja. Selain itu pembuatan sistem pakar ini juga dapat dilakukan dengan lebih efektif (cepat).

3. Sistem pakar ini dapat memberikan solusi dari penyakit penderita Tuberkulosis paru dan tuberculosis kelenjar.

\section{Saran}

1. Sistem pakar tersebut dapat dikembangkan dengan metode yang lain untuk menambah keakuratan data untuk penderitapenyakit tuberkulosis.

2. Sistem pakar tersebut diperlukan adanya penambahan data untuk lebih 
menambah pengetahuan dan wawasan dari sistem pakar penyakit tuberculosis.

3. Fasilitas yang tersedia oleh sistem aplikasi ditambah lebih banyak dengan melibatkan pihak-pihak kesehatan yang bersangkutan untuk memberikan solusi bagi pengguna umum mengenai penyakittersebut.

\section{DAFTRA PUSTAKA}

Dhimas, P.S., Eko, B.S. 2013. Sistem Pendukung Keputusan Revitalisasi terhadap Bangunan Dan KAwasan cagar Budaya Kota Bandung Di Disbudpar Kota Bandung. Vol.2, No.2, Oktober 2013. ISSN:2089-9033.

Gia, Anggraini., Siti, A., Eka P.W.,2014. Rancang Bangun Aplikasi Pengenalan Pariwisata Sumatra Selatan Berbasis Sistem Opersi Android. ISSN:24071102.

Hayadi, H. 2016. Sistem Pakar.Yogyakarta : CV Budi Utama. ISBN:978-602-401090-4.

Hidaya, R. 2014. Sistem Informasi Ekspedisi Barang Dengan Metode E-CRM Untuk Meningkatkan Pelayanan Pelanggan. Vol.4 No. 2/ September 2014. ISSN:2088-1762.

Isnandi.,Indah,U.P. 2014. Sistem Informasi Penjualan Tiket Pada Al fath Tours dan Travel Pacitan. Sentra Penelitian Engginering Dan Edukasi Volume 11 No 2-2014. ISSN:1979-9330.

Iswandy, E. 2014.Perancangan Sistem Informasi tentang Pencatatan Hasil Tes kemampuan Fisik Atlet.Vol.2 No. 2 Oktober 2014. ISSN:2338-2724

Kadek, D.G.S., Ida, N.S. 2014.Sistem Pakar Diagnosa Awal Penyakit Kulit Pada Sapi Bali Dengan Menggunakan Metode Forward Chaining. Volume 3, Nomor3, Desember 2014. ISSN: 2089-8673.

Kunoli, $\quad$ F.J. 2012.Penyakit TropisYogyakarta : CV Andi Offset. ISBN:978-979-29-3416-8.

Kusnadi, A. 2013.Perancangan Aplikasi Sistem Pakar untuk mendiagnosa penyakit pada manusia.Ultimatics, Vol.4 No.1 Juni 2013. ISSN: 20854552.

Maretanata, T., Dian, D., Feby, E. 2014.Perencanaan kebutuhan tempat tidur di rumah sakit paru Jember
Tahun 2013-201 .Vol.2, No.1, Maret 2014. ISSN:2337-585X

Meiska, F.M., Arief, L.N., Bandi, S.2014. Desain Aplikasi Sistem Informasi Pelanggan PDAM Berbasis WebGIS.Volume 3 Nomor 3 September 2014. ISSN: 2337-845X.

Mujilahwati, S. 2014. Diagnosa Penyakit Tanaman Hias Mengguanakan Metode Certainty Factor Berbasis Web. Jurnal Teknika Vol 6 No 2 September 2014. ISSN:2085-0859.

Nur, P.Y., dan Abdul, F. 2013. Sistem Pakar untuk Mendiagnosa Penyakit Pencernaan Menggunakan Metode Dempster Shafer. Volume 1, Nomor 1, Juni 2013. ISSN: 2338-5197.

Octavia, R.P. 2013. Analisis Perlakuan Akuntansi untuk Website pada Bank SULUT (PERSERO) Manado.Vol.1 No. 3 September 2013. ISSN: 2303-1174.

Opik, T.K., Mohammad I., Ai, N. 2013. Pembuatan Aplikasi Anbiyapedia Ensiklopedia Muslim Anak Berbasis Web.Edisi Juli 2013 Volume VII No1. ISSN:1979-8911.

Pasaribu, J.S. 2015.Implementasi Sistem Pakar Untuk Diagnosa Penyakit mata Pada Manusia. Yogyakarta, 28 Maret 2015. ISSN: 2089-9815.

Puput, S.D., Ryana D.L., Ryani T.L. 2015.Sistem pakar diagnosis penyakit ikan koi dengan metode Bayes.Vol.4, No.1, Maret 2015. ISSN: 2089-9033.

Purnamayudha, O. 2015. Aplikasi Sistem Informasi Penujalan Obat Di Apotek Dengan Menggunakan Metode Visual Basic 6. JEMIS Vol. 3 No. 2 tahun 2015. ISSN: 2338-3925.

Rizki, A.P., Antok S., Pantjawati S. 2014.Rancang Bangun Sistem Informasi Manajemen Arsip Rumah Sakit Bedah Surabaya Berbasis Web.JSIKA Vol3, No 1 (2014). ISSN:2338-137X.

Rosnelly, R. 2012. Sistem Pakar Konsep dan Teori.Yogyakarta : CV Andi Offset. ISBN:978-979-29-3416-8.

Rulia, P.H., Bambang, E.P., Indah. 2015. Sistem Penjualan Berbasis Web (ECommerce) Pada Tata distro Kabupaten Pacitan. Jurnal Bianglala Informatika Vol 3 No 2 September 2015. ISSN: 2338-8145. 
Sayyidah, F., Suryatiningsih., Siska, K.S. 2015. Aplikasi Diagnosis Kelainan Reflaksi Mata dan Tips perawatan Mata dengan Metode Forward. Vol.7 No. 2 November 2015. ISSN:20853688.

Setyowati, D.,Yudha, I.P. 2013. Sistem Pakar Diagnosa Penyakit Tanaman Padi berbasis WEB . Vol.6, No.1, Agustus 2013. ISSN:1979-8415.
Sitorus, L. 2015. Algoritma Dan Pemrograman.Yogyakarta : CV.Andi Offset.

Supardi, Y. 2013. Koleksi Program Tugas Akhir Dan Skipsi Dengan FoxPro9.Jakarta : PT.Elex Media Komputindo.

Suwondo, A. 2014.Aplikasi Sistem Informasi Perpustakaan di Smk Takhassus Kalibeber Wonosobo. Jurnal PPKM UNSIQ I (2014) 31-39. ISSN:2354-869x. 